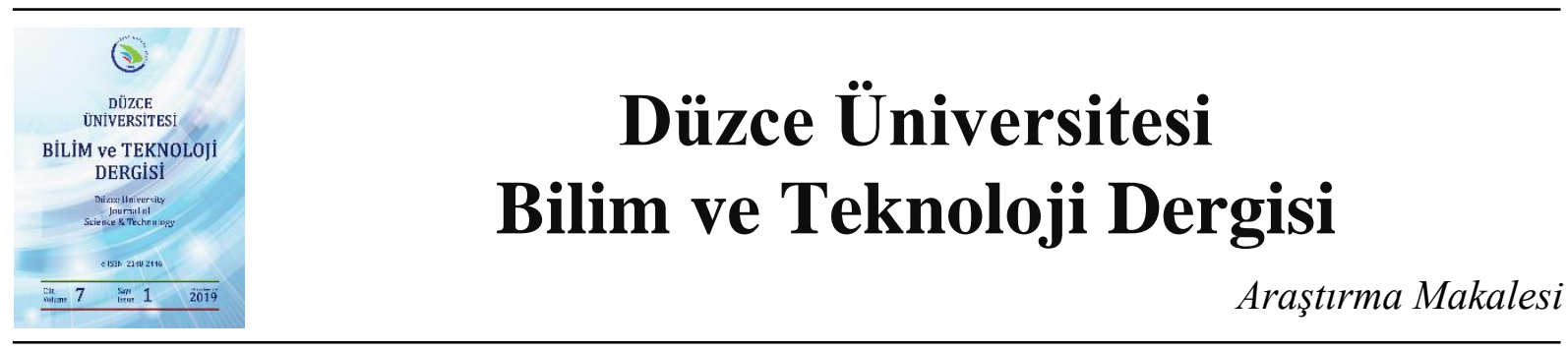

\section{Portakal (Citrus sinensis) Kabuğundan Elde Edilen Hidrosol/Esansiyel Yağların Antimikrobiyal ve Antioksidan Özellikleri}

\author{
Dilara Nur DİKMETAŞ a, Güliz KONUŞUR a , Ayşegül MUTLU İNGÖK ${ }^{\text {a,b,* }}$, Zehra GÜLSÜNOĞLU a , Funda \\ KARBANCIOĞLU GÜLER ${ }^{a}$ \\ ${ }^{a}$ Gıda Mühendisliği Bölümü, Kimya Metalurji Fakültesi, İstanbul Teknik Üniversitesi, İstanbul, TÜRKIYYE \\ ${ }^{b}$ Gıda Teknolojisi Bölümü, Akçakoca Meslek Yüksekokulu, Düzce Üniversitesi, Düzce, TÜRKIYE \\ * Sorumlu yazarın e-posta adresi: aysegulmutlu@duzce.edu.tr
}

\begin{abstract}
ÖZET
$\mathrm{Bu}$ çalışmada Dalaman, Köyceğiz ve Finike'de yetişmiş portakalların kabuklarından elde edilen hidrosol ve esansiyel yağların Staphylococcus aureus (ATCC 25923) ve Escherichia coli (ATCC 25922) bakterilerine karş1 antimikrobiyal etkileri kuyucuk difüzyon metodu ile incelenmiştir. Antimikrobiyal etkinin yanında portakal kabuğu hidrosollerinin antioksidan aktivitesi de CUPRAC (Bakır(II) iyonu indirgeme esaslı antioksidan kapasite) ve DPPH (1,1-diphenyl-2-picrylhydrazyl) serbest radikal yakalayıcı yöntemi ile incelenmiştir. Hidrosollerin $E$. coli (ATCC 25922) ve S. aureus (ATCC 25923) bakterilerine karşı gösterdiği inhibisyon zonları esansiyel yağlara kıyasla daha küçük olmakla birlikte aralarındaki fark istatistiksel açıdan önemli bulunmamıştır. En yüksek antimikrobiyal aktiviteye sahip olan distilat, Dalaman portakalının kabuğundan elde edilen olmuştur. Antioksidan analizleri sonucunda ise hidrosollerin antioksidan aktivite değerleri CUPRAC ve DPPH metotlarında sirasıyla 8 $\mu \mathrm{g}$ Troloks eşdeğeri/mL ve $3 \mu \mathrm{g}$ Troloks eşdeğeri/mL olarak bulunmuştur. İnhibisyon yüzdesi \%3 civarlarında olan Dalaman portakallarından elde edilen hidrosollerin antioksidan aktiviteye sahip olduğu ancak sentetik antioksidan olan BHT ile karşılaştırıldığında düşük bir yüzdeye sahip olduğu görülmektedir. Bu sonuçlardan yola çıkılarak 3 farklı bölge portakalının kabuğundan elde edilen hidrosol ve esansiyel yağların Staphylococcus aureus (ATCC 25923) ve Escherichia coli (ATCC 25922) bakterilerine karşı sentetik antioksidanlara kıyasla daha düşük düzeylerde olmakla birlikte antimikrobiyal ve antioksidan etki gösterdiği saptanmıştır.
\end{abstract}

Anahtar Kelimeler: Hidrosol, Esansiyel yă̆, Antimikrobiyal aktivite, Antioksidan aktivite

\section{Antimicrobial and Antioxidant Properties of Hydrosol/Essential Oils Obtained from Orange (Citrus sinensis) Peels}

\begin{abstract}
In this study, antimicrobial activity of essential oils and hydrosols from fresh orange peels which were cultivated in Dalaman, Köyceğiz and Finike against Staphylococcus aureus (ATCC 25923) and Escherichia coli (ATCC 25922) were examined by using the agar well diffusion method. In addition to antimicrobial activity, antioxidant activities of orange peel hydrosols were also determined by cupric reducing antioxidant capacity (CUPRAC) and
\end{abstract}


radicals scavenging ability of DPPH (1,1-diphenyl-2-picrylhydrazyl) methods. Although, the inhibition zones of hydrosols against E. coli (ATCC 25922) and S. aureus (ATCC 25923) bacteria were smaller than essential oils, the difference between them was not statistically significant. The highest antimicrobial activity has been obtained from the peel of oranges from Dalaman. As a result of antioxidant capacity analysis, the concentration of hydrosols was found as $8 \mu \mathrm{g}$ Trolox equivalent $/ \mathrm{mL}$ and $3 \mu \mathrm{g}$ Trolox equivalent/mL in CUPRAC and DPPH methods, respectively. Although, Dalaman hydrosols have an antioxidant activity with 3\% inhibition percentages, when compared with the synthetic antioxidant BHT, it was observed at lower levels. On the basis of this experiment, hydrosol and essential oils obtained from oranges cultivated from 3 different regions have antioxidant and antimicrobial activities against Staphylococcus aureus (ATCC 25923) and Escherichia coli (ATCC 25922). However, antioxidant activity is lower when compared with the synthetic antioxidant.

Keywords: Hydrosol, Essential oil, Antimicrobial activity, Antioxidant activity

\title{
I. GiRIS
}

\begin{abstract}
A BD'de her yıl 46 milyon insan gida kaynaklı hastalıklara yakalanmakta ve bunlardan 3000'i ise hayatını kaybetmektedir. Gıda kaynaklı hastalıklara ve ölümlere neden olan en önemli bakteriler; Escherichia coli, Staphylococcus aureus, Campylobacter jejuni, Salmonella spp., ve Listeria monocytogenes olarak bildirilmektedir. Gıda üreticileri de; gida kaynaklı enfeksiyonların ve hastalıkların önüne geçmek ve gıdanın kalitesini koruyabilmek için mikroorganizmaları azaltmaya veya ortadan kaldırmaya çalışmaktadırlar [1]. E. coli $\mathrm{O} 157: \mathrm{H} 7$; dünya çapında en yüksek ölüm oranlarına sahip en toksijenik serotiptir ve aynı zamanda ciddi salgınlara neden olabilen en yaygın bakteriyel patojenlerdendir [2]. Gıdalardaki S. aureus tarafindan üretilen enterotoksinler tüm dünyada görülen stafilokokal hastalıklara neden olmaktadır. Günümüzde $S$. aureus'un sebep olduğu gıda zehirlenmeleri Amerika'da ikinci, Fransa'da ise üçüncü sırada yer almaktadır. Gıdada kontaminasyona sebep olan bu bakterinin en büyük taşıyıcısı insanlar olup, diğer faktörler olarak da hava, toz ya da gıda temas yüzeyleri gösterilebilir [2].
\end{abstract}

Sentetik antimikrobiyal ajanlarının yan etkilerinin yaygınlığındaki artış ve ilaçlara direnç gösteren bakterilerin varlığı; bilim insanlarını bitki bazlı antimikrobiyaller için araştırmaya yönlendirmiştir. Esansiyel yağlar ve bunların yan ürünleri de geleneksel tıpta yaygın olarak kullanılmaktadır. Bu nedenle de bulaşıcı hastalıkların tedavisi için potansiyel bir kullanımı olduğu düşünülmekte ve bu konu üzerinde araştırmalar yapılmaktadır [3]. Ayrıca geleneksel ilaçlar ve sentetik antimikrobiyaller ile ilgili sınırlandırmalar da bitki bazlı alternatiflere yönelimi artıırmıştır. Bunun sonucunda yapılan çalışmalarda doğal biyoaktif maddelerin kaynağı olan bitkilerin farklı ekstraktları üzerine yoğunlaşılmıştır; zira bunlar da hem biyolojik olarak zengin içeriğe sahiptir hem de toksik etkisi bulunmamaktadır [4]. Bitkisel esansiyel yağlarda beklenen antimikrobiyal aktivite monoterpenler, seskiterpenler, hidrokarbonlar ve fenoller gibi biyoaktif maddelerin varlığından kaynaklanır [5].

Buna ek olarak tüketicilerin doğal ürünler konusundaki kaygısi; sentetik antimikrobiyallerin yerine doğal antimikrobiyallerin kullanımlarının yanı sıra doğal antioksidanlara duyulan ihtiyacı da ortaya çıkarmıştır. Doğal antioksidanlar hastalıkların önlenmesi için yararlı maddeler olarak kabul edilir. Yapılan birçok çalışmada bitki esansiyel yağlarında bulunan fenolik bileşenlerin radikal yakalayıcı kapasitelerinin bir sonucu olarak da antioksidan aktivite gösterdiklerini ifade etmektedir. Yüksek fenolik bileşen oranı, doğal antioksidan olarak kullanılabileceği sonucunu doğurmuştur [6]. 
Aromatik bitkilerin damıtma işlemi sonucunda beş farklı ürün açığa çıkar. Bunlar; esansiyel yağ, damıtılmış biyokütle, damıtmadan kaynaklı kül, atık su ve hidrosollerdir [7]. Hidrodistilasyon sonucunda toplanan iki fazdan biri uçucu bileşiklerin ana kısmını oluşturan esansiyel yağ; diğer faz ise düşük oranda esansiyel yağ içeren hidrosol fazıdır [7, 8]. Hidrosol üretiminin kolay olması, ucuz olması ve vücutta herhangi bir etki bırakmaması nedeniyle doğal antimikrobiyal ajan olarak kullanımı ortaya çıkmıştır [9]. Aynı zamanda hidrosollerin, GRAS (Generally Recognized as Safe) statüsünde yer almasından dolayı gıda uygulamalarında kullanılmasında herhangi bir sakınca yoktur [10].

Bitkilerden hidrosol eldesi Clevenger tipi aparatta hidrodistilasyona tabi tutularak gerçekleştirilir ve hidrosol kompozisyonu GC-MS ile analiz edilebilir [11]. Citrus sinensis türünden elde edilen hidrosollerin kimyasal kompozisyonları daha önceki çalışmalarda belirlenmiştir. Ana bileşenler olarak, $\% 44,1$ oranında linalool, $\% 23,7$ oranında $\alpha$-terpineol ve \%5,7 cis-linalool oksit bulunmuştur [8]. Ndiaye ve diğ., [12]'nin yaptığ 1 bir diğer çalışmada ise yine benzer olarak linalool Citrus sinensis'den elde edilen hidrosolün ana bileşeni olarak bulunmuştur.

Gerçekleştirilen çalışmada farklı portakal çeşitlerinin kabuklarından elde edilen hidrosol ve esansiyel yağların antimikrobiyal etkilerinin ve hidrosollerin antioksidan özelliklerinin incelenmesi amaçlanmıştır.

\section{MATERYAL Metot}

\section{A. PORTAKALLAR (Citrus sinensis) VE MIKROORGANIZMALAR}

$\mathrm{Bu}$ çalışma için Finike, Dalaman ve Köyceğiz menşeili portakalların (Citrus sinensis) kabuklarının antimikrobiyal etkileri Staphylococcus aureus (ATCC 25923) ve Escherichia coli (ATCC 25922) bakterilerine karşı incelenmiştir. Bakteri kültürleri Yıldız Teknik Üniversitesi, Gıda Mühendisliği Bölümünden temin edilmiş ve İstanbul Teknik Üniversitesi, Gıda Mühendisliği Bölümünde $-80{ }^{\circ} \mathrm{C}$ 'de gliserol çözeltisi içerisinde muhafaza edilmiştir. Analiz öncesinde Tryptic Soy Broth besiyerinde çoğaltılmıştır.

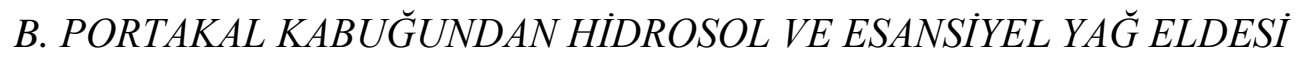

Hidrosoller, portakal kabuklarının Clevenger tipi aparatla hidrodistilasyonu sonucu elde edilmiştir. Portakal kabukları soyulduktan sonra yaklaşık $3 \mathrm{~mm}$ boyutunda kesilmiştir. Saf su ilavesinden sonra distilasyon ünitesinde $150^{\circ} \mathrm{C}$ 'de 4 saat bekletilmiştir. Distilasyon sonucunda toplanan iki fazdan alttaki faz hidrosol, üstteki faz ise esansiyel yağ olarak değerlendirilmiştir. Ayrı olarak toplanan hidrosol ve esansiyel yağlar kullanıma kadar steril koyu renk şişelere alınmış ve buzdolabında $+4{ }^{\circ} \mathrm{C}$ 'de saklanmıştır. Elde edilen esansiyel yağlar analiz için kullanılmadan önce susuz sodyum sülfat ile kurutulmuştur [13]. Kurutma işleminden sonra santrifüj uygulanarak esansiyel yağların katı fazdan ayrımı kolaylaştırılmıştır. Çalışma 3 tekrar ve 3 paralel olacak şekilde yürütülmüştür. 


\section{ANTIMIKROBIYAL AKTIVITE ANALIZLERI}

Hidrosollerin ve esansiyel yağların antimikrobiyal aktivite analizleri Acheampong ve diğ., [3] ile Deans ve Ritchie [14] tarafından belirlenen yöntemlerin kullanılması ile gerçekleştirilmiştir. Bakteri kültürleri Tryptic Soy Broth besiyerinde $35{ }^{\circ} \mathrm{C}$ 'de 24 saatlik inkübasyon sonucu geliştirilmiş ve bakteri konsantrasyonları $10^{6}$ adet/mL'ye ayarlanmıştır. Konsantrasyonuna ayarlanmış bakteri kültürleri, Tryptic Soy Agar (TSA-Merck HGaA) üzerine $100 \mu \mathrm{L}$ olarak ekilmiştir. Kuruması için beklendikten sonra delme seti ile $6 \mathrm{~mm}$ çapında petri kabının ortasına 1 adet kuyucuk açılmıştır. Açılan bu kuyucuklara her bir hidrosolden $50 \mu \mathrm{L}$, her bir esansiyel yağ için ise $10 \mu \mathrm{L}$ olacak şekilde eklenmiş ve $37{ }^{\circ} \mathrm{C}$ 'de 24 saat inkübasyona bırakılmıştır. Antimikrobiyal aktivite, kuyucukların $(6 \mathrm{~mm})$ etrafında oluşan inhibisyon bölgesinin çapının milimetre olarak ölçülmesiyle değerlendirilmiştir. Referans madde olarak $0,5 \mathrm{mg} / \mathrm{mL}$ konsantrasyonunda streptomisin kullanılmıştır.

\section{ANTIOKSIDAN AKTIVITE ANALIZLERI: CUPRAC METODU}

Bu yöntemde polifenolün bakır (II) iyonunu indirgeme kabiliyeti Apak ve diğ. [15]'nin tanımlamış olduğu yönteme göre belirlenmiş̧tir. Bu yöntem temel olarak, neokuproinin bakır (II) ile oluşturduğu bakır (II) neokuproin kompleksinin $450 \mathrm{~nm}$ dalga boyunda maksimum absorbans veren bakır (I) neokuproin çelatına indirgenmesine dayanmaktadır [16]. Analiz için, $100 \mu \mathrm{L}$ hidrosol üzerine $1 \mathrm{~mL}$ $\mathrm{CuCl}_{2}(0,01 \mathrm{mM}), 1 \mathrm{~mL} \mathrm{NH}{ }_{4} \mathrm{Ac}$ tampon çözeltisi (pH 7), $1 \mathrm{~mL}$ neokuproin çözeltisi $(7,5 \mathrm{mM})$ ve $1 \mathrm{~mL}$ su eklenerek 30 dakika boyunca oda koşullarında karanlıkta bekletilmiştir. Örneklerin absorbansı 450 nm dalga boyunda spektrofotometre kullanılarak ölçülmüştür. Kalibrasyon eğrisi, 0; 0,002; 0,005; 0,01; 0,02 ve $0,04 \mathrm{mg} / \mathrm{mL}$ Troloks konsantrasyonları kullanılarak hazırlanmıştır. Sonuçlar $\mu \mathrm{g}$ Troloks eşdeğeri (TE)/mL hidrosol cinsinden verilmiştir. Analizler 3 tekrar ve 3 paralel olacak şekilde gerçekleştirilmiştir.

\section{E. ANTIOKSIDAN AKTIVITE ANALIZLERI: DPPH METODU}

$\mathrm{Bu}$ yöntemde kararlı bir radikal olan DPPH kullanılmaktadır ve antioksidanların bu serbest radikali yakalama yeteneği ölçülerek antioksidan aktivite tayini yapılmaktadır. Bu analiz DPPH radikallerinin antioksidanlar ile reaksiyona girip 1,1-difenil-2-pikrihidrazin'e indirgenmesi prensibine dayanmaktadır. DPPH analizi için, $2 \mathrm{~mL}$ 0,1 mM'lık DPPH üzerine $100 \mu \mathrm{L}$ hidrosol ilave edilmiş ve 10 saniye boyunca çalkalanmış ve 30 dakika oda koşullarında karanlıkta bekletilmiştir. Örneklerin absorbans1 $517 \mathrm{~nm}$ dalga boyunda spektrofotometre kullanılarak okunmuş ve kaydedilmiştir. Kalibrasyon eğrisi $0 ; 0,002 ; 0,005 ; 0,01 ; 0,02$ ve $0,04 \mathrm{mg} / \mathrm{mL}$ Troloks konsantrasyonlarında hazırlanmıştır. Sonuçlar $\mu \mathrm{g}$ Troloks eşdeğeri (TE)/mL hidrosol cinsinden verilmiştir. DPPH radikalinin inhibisyon yüzdesi (\%I) ise aşağıdaki Eşt. 1'e göre hesaplanmıştır [17]. Analizler 3 tekrar ve 3 paralel olacak şekilde gerçekleştirilmiştir.

$$
\% \mathrm{I}=\frac{\mathrm{ABS}_{\text {blank }}-\mathrm{ABS}_{\text {örnek }}}{\mathrm{ABS}_{\text {blank }}} \times 100
$$

\section{F. ISTATISTIKSSEL ANALIZZ}

Elde edilen hidrosol ve esansiyel yağların antimikrobiyal ve hidrosollerin antioksidan etkileri 0,05 önem düzeyinde tek yollu ANOVA ile araştırılmıştır. Ortalamaların karşılaştııılmasında Duncan çoklu aralık 
testi kullanılmıştır. İstatistiksel analizler SPSS (IBM SPSS STATICS 20) programı ile gerçekleştirilmiştir.

\section{BULGULAR VE TARTIȘMA}

\section{A. ANTIMIKROBIYYAL AKTIVITE}

Üç farklı bölgede yetişmiş portakaldan elde edilen hidrosollerin antimikrobiyal etkisi hem Gram (+) hem Gram (-) bakterilere karşı incelenmiştir. Dalaman, Köyceğiz ve Finike portakallarından elde edilen hidrosoller ve esansiyel yağlar S. aureus (ATCC 25923) ve E. coli (ATCC 25922) bakterilerine karş1 inhibe edici özellik göstermiştir (Tablo 1). Hidrosollerin E. coli (ATCC 25922) ve $S$. aureus (ATCC 25923) bakterilerine karşı gösterdiği inhibisyon zonları esansiyel yağlara kıyasla daha küçük olmakla birlikte aralarındaki fark istatistiksel açıdan önemli değildir $(p>0.05)$. Dalaman, Finike ve Köyceğiz'de yetişmiş portakallar arasında da antimikrobiyal aktivite açısından istatiksel farklılık yoktur $(p>0.05)$. Bu analizlerin yanında hidrosol/esansiyel yağ ve mikroorganizma kontrolleri de yapılmıştır. Hidrosol/esansiyel yağ kontrolünde herhangi bir mikroorganizma gelişmesi belirlenemezken, mikroorganizma kontrollerinde de bakterilerin normal olarak geliştiği gözlemlenmiştir.

Tablo 1. Portakal hidrosol ve esansiyel yağlarının gösterdiği antimikrobiyal aktivite

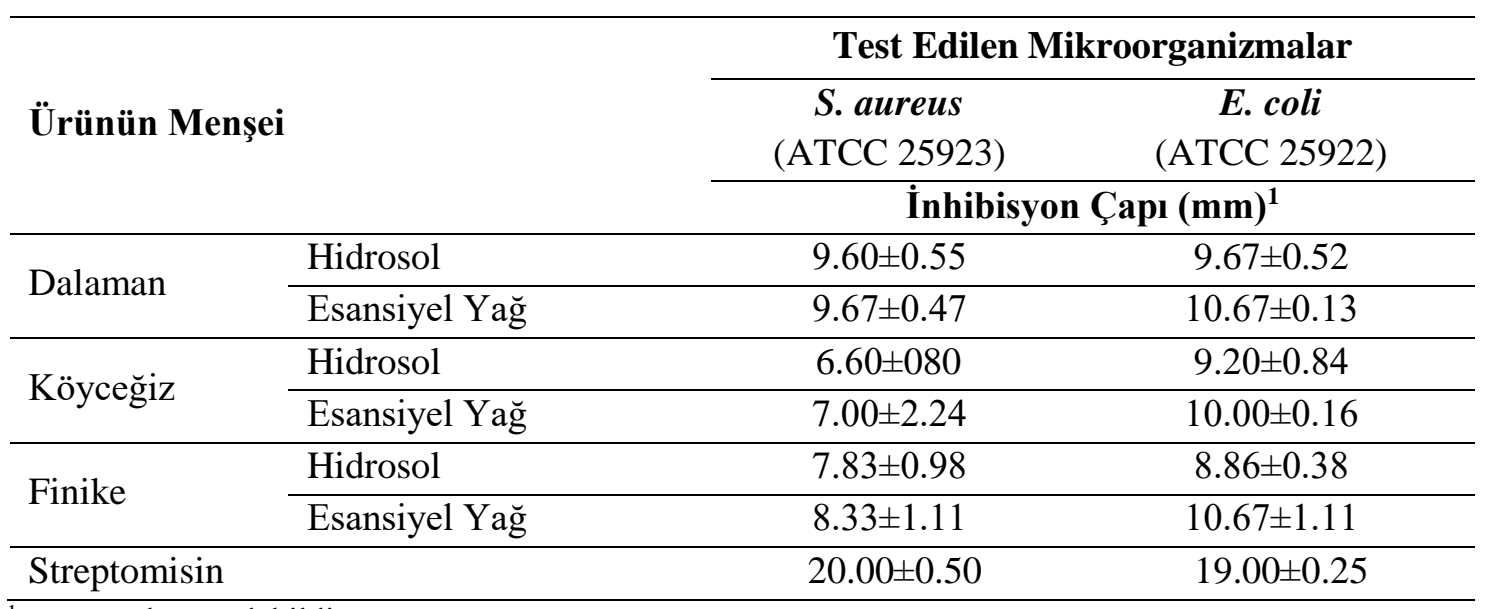

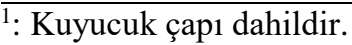

Acheampong ve diğ. [3]'nin yaptığı çalışmada Gana'da yetişmiş portakalın hem taze hem de kurutulmuş kabuklarından elde edilen hidrosollerin $E$. coli ve $S$. aureus bakterilerine karşı herhangi bir antimikrobiyal etki oluşturmadığı belirtilmiştir. Espina ve diğ. [18] yaptı̆̆ çalışmada ise İspanya'dan alınan $C$. sinensis (portakal), C. lemon (limon) ve C. reticulata (mandalina)'nın esansiyel yağının 6 farklı mikroorganizmaya karşı aktivitesi incelendiğinde sadece mandalinanın antimikrobiyal etkisinin olduğunu ifade etmişlerdir. Bunun sebebi olarak da limon ve portakalda $\% 5$ civarında bulunan oksijenli monoterpenin mandalinada \%13 civarlarında bulunması gösterilmiştir. Bu çalışmada kullanılan Türkiye'de yetişmiş portakallardan elde edilen hidrosollerde ve esansiyel yağlarda antimikrobiyal etki görülmüştür. Bu farklılıkların nedeni olarak farklı toprak, iklim ve yetişme koşullarında olması ve dolayısıyla bu faktörlerin portakalın kompozisyonunda etken maddelerde farklılıklar oluşturması gösterilebilir [19]. 
Gram (-) bakteriler içerdikleri kompleks çift katmanlı hücre zarı nedeniyle Gram (+) bakterilerden daha dayanıklı olmasına rağmen gerçekleştirilen analizler sonucunda $E$. coli bakterisine karşı daha yüksek inhibisyon çapı oluşturduğu ve Gram (+) karakterdeki $S$. aureus bakterisinin çalış1lan esansiyel yağ ve hidrosollere kaşı daha güçlü bir direnç gösterdiği tespit edilmiştir. Benzer şekilde başka bir çalışmada C. aurantium'dan elde edilen esansiyel yağın da $S$. aureus bakterisine karşı inhibe edici etkisi belirlenmezken, $E$. coli bakterisine karşı ise antimikrobiyal aktivite gösterdiği ifade edilmiştir. $\mathrm{Bu}$ sonuçlardan yola çıkarak hücre zarı katmanlarının antimikrobiyal etkide herhangi bir seçici etki yaratmadığı sonucuna ulaşılabildiği ifade edilmiştir [13].

\section{B. ANTIOKSIDAN AKTIVITE}

Dalaman, Köyceğiz ve Finike portakallarından elde edilen hidrosollerin antioksidan aktiviteleri iki farklı metot ile incelenmiştir. CUPRAC ve DPPH analizleri sonucunda belirlenen antioksidan aktivite sonuçları Tablo 2'de gösterilmiştir. CUPRAC ve DPPH analiz sonuçlarına göre her iki analizde de en yüksek antioksidan konsantrasyonu Dalaman portakalından elde edilen hidrosollerde gözlenirken, en düşük antioksidan konsantrasyonu ise Köyceğiz portakal kabuğu hidrosolünde görülmüştür. Bununla birlikte Dalaman ve Finike ile Köyceğiz ve Finike portakallarından elde edilen hidrosollerin antioksidan aktiviteleri arasındaki fark istatistiksel olarak önemli bulunmamıştır $(p>0.05)$.

Tablo 2. C. sinensis hidrosollerinin gösterdiği antioksidan aktivite

\begin{tabular}{|c|c|c|}
\hline \multirow[b]{2}{*}{ Ürünün Menşei } & \multicolumn{2}{|c|}{ Kullanılan Metot } \\
\hline & $\begin{array}{c}\text { CUPRAC } \\
\text { ( } \mu \mathrm{g} \mathrm{TE} / \mathrm{mL} \text { hidrosol) }\end{array}$ & $\begin{array}{c}\text { DPPH } \\
\text { ( } \mu \mathrm{g} \text { TE/mL hidrosol) }\end{array}$ \\
\hline Dalaman & $12,02 \pm 1,35^{\mathrm{a}}$ & $4,93 \pm 0,85^{\mathrm{a}}$ \\
\hline Köyceğiz & $3,17 \pm 1,86^{\mathrm{b}}$ & $0,13 \pm 0,13^{\mathrm{b}}$ \\
\hline Finike & $9,01 \pm 4,95^{\mathrm{ab}}$ & $3,82 \pm 2,92^{\mathrm{ab}}$ \\
\hline
\end{tabular}

Analizler sonucu elde edilen değerlere göre hesaplanan DPPH radikallerinin inhibisyon yüzdesi ise Şekil 1'de gösterilmiştir. Aynı zamanda hidrosollerin antioksidan aktivitelerine göre hesaplanan inhibisyon yüzdeleri de sentetik antioksidan olan BHT ile karşılaştırılmıştır. CUPRAC metodu ile yapılan analizde Finike hidrosolünün konsantrasyonu $9.01 \mu \mathrm{g}$ TE/mL hidrosol bulunurken DPPH metodu ile yapılan analizler sonucunda da $3.82 \mu \mathrm{g}$ TE/mL hidrosol bulunmuştur. Dalaman portakalının hidrosollerinin inhibisyon yüzdesi $\% 2,8$ ile $\% 4,4$ arasında değişirken, Finike portakalının hidrosolleri ise $\% 0-4,9$ arasında inhibisyon yüzdesine sahiptir. Köyceğiz portakalının hidrosolü ise $\% 0,176$ inhibisyon yüzdesiyle en düşük inhibisyon aktivitesine sahiptir. BHT'nin \% inhibisyon değeri 18,71 olarak alınmıştır [20]. Bu değerler BHT sentetik antioksidanı ile karşılaştırıldığında $C$. sinensis hidrosollerinin daha düşük olmakla birlikte antioksidan aktiviteye sahip olduğu, bununla birlikte en güçlü antioksidan aktivitenin Dalaman portakalı kabuğundan elde edilen hidrosolde olduğu tespit edilmiştir. Yapılan analizler sonucunda hidrosollerin bir miktar antioksidan aktiviteye sahip olduğu ancak sentetik antioksidanlar kadar etkili olmadığ sonucuna varılmıştır (Şekil 1). 


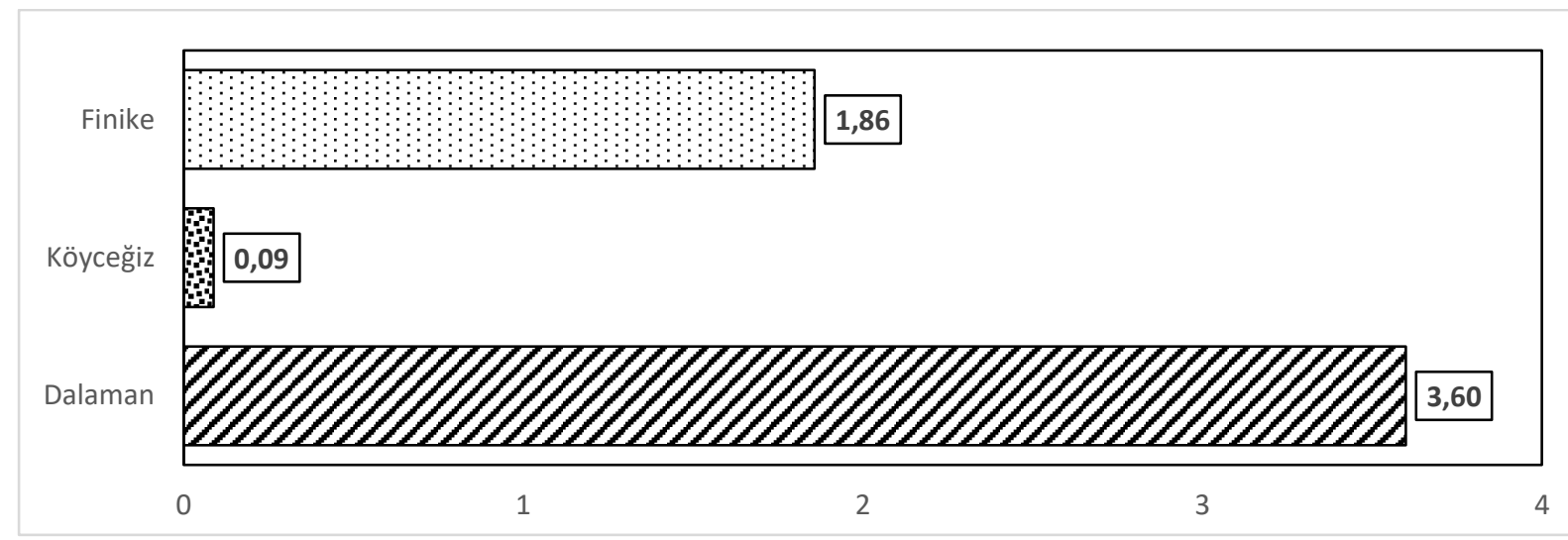

Şekil 1. Portakal hidrosollerinin inhibisyon yüzdeleri

Bendaha ve diğ. [21] yaptığı çalışmada ise $C$. aurantium (turunç) esansiyel yağının antioksidan aktivitesini askorbik asitle karşılaştırmış ve askorbik asite göre çok düşük bir aktiviteye sahip olduğu sonucuna ulaşmıştır. Portakaldan elde edilen hidrosol ve esansiyel yağlar sentetik antioksidanlar yerine kullanılabilecek düzeyde antioksidan aktivite göstermese de serbest radikallerin vücuda vereceği hasarlara ve bazı hastalıklara karşı koruyucu etkiye sahiptir [22]. Yüksek radikal yakalayıcı etki yüksek oranda oksijenli monoterpen içeriği ile ilişkilendirilir. Limonen ve mirsen içermeyen, $\gamma$-terpinen ve terpinolen açısından zengin bir içeriğe sahip terpenler radikal yakalayıı etkiyi arttırmaktadır [22].

Aynı bitkiden elde edilen hidrosol ve esansiyel yağın antioksidan aktivitelerini karşılaş̧ırırken en önemli kriterlerden biri kompozisyonlarındaki farktır. Oksijenli monoterpen oranının yüksek olduğu ekstrakt daha yüksek antioksidan aktivite gösterir. Calendula arvensis türünden elde edilen hidrosolün $(\% 93,7)$ esansiyel yağına (\%62) göre daha fazla oksijenli monoterpen içerdiği için hidrosolün antioksidan aktivitesi daha yüksek bulunmuştur [23]. Portakaldan elde edilen hidrosol ve esansiyel yağların komposizyonu karşılaştırıldığında ise hidrosolünün esansiyel yağa göre daha fazla oksijenli monoterpen içerdiği bulunmuştur [12].

Farklı yerlerde yetişmiş portakalların kompozisyonuna bakıldığında ise bileşen sayılarında farklılık bulunduğu belirtilmiştir. Ayrıca bileşen bazında bakıldığında da bu farklılıklar dikkat çekmektedir. Örneğin; Tunus, Cezayir ve Türkiye portakallarının bileşen sayıları farklı olmakta ve limonen oranı da Tunus ve Türkiye' de $\% 90$ civarlarında iken Cezayir portakalında $\% 2$ ile $\% 7$ arasında değişmektedir [21]. Coğrafi konum, çevre ve olgunlaşma düzeyi gibi birçok etken bitkilerden elde edilen esansiyel yă̆ ve hidrosolün kompozisyonunu etkilemektedir. Bu kompozisyondaki farklılık ise hem antimikrobiyal aktivite hem de antioksidan aktivitedeki farklılıklara neden olarak gösterilebilir [19].

\section{SONUC}

Son zamanlarda günden güne etkisi artmakta olan gıda kaynaklı hastalıklar hem üretici hem de tüketici için ciddi bir problem oluşturmaktadır. Bu duruma paralel olarak gıda güvenliğini sağlamaya yönelik araştırmalar da günden güne artış göstermektedir. Ayrıca hastalıklara neden olan mikroorganizmaların gösterdiği direnç de artış gösterdiğinden bu konunun çözümü için de farklı araştırmalara yoğunlaşılmıştır. Günümüzde tercih edilen sentetik antioksidan ve antimikrobiyallerin vücutta bıraktığ1 yan etkiler ve güvenilir olmadığına dair şüpheler; doğal ajanların araştırılmasına neden olmuştur. $\mathrm{Bu}$ nedenle de bitkilerin içeriğinde bulunan fenolik bileşenlerin varlı̆̆ düşünülerek esansiyel yağ ve 
hidrosoller üzerine yoğunlaşılmıştır. Özellikle bitkilerden elde edilen esansiyel yağ ve hidrosollerin kimyasal kompozisyonu üzerine odaklanılarak bunların antimikrobiyal ve antioksidan özellikleri incelenmiştir. Yağ ve hidrosollerin kompozisyonuna göre sahip oldukları aktivite değişkenlik göstermektedir. Yapılan çalışmalarda farklı coğrafi koşullarda yetişen aynı bitkinin kimyasal kompozisyonunda değişiklik gözlenebileceği ve buna bağlı olarak da antimikrobiyal ve antioksidan aktivitenin de etkilenebileceği belirtilmiştir. Fenoller içerisinde bulunan oksijenli monoterpen ve limonenen oranı yağ ve hidrosolün antimikrobiyal ve antioksidan kapasitesini etkilemektedir. Esansiyel yağ ve hidrosoller gıda endüstrisinde pek çok alanda kullanılabilir. Son zamanlarda özellikle gıda ambalajlamasında esansiyel yağların antimikrobiyal ve antioksidan özelliklerinden yararlanılmaktadır. $\mathrm{Bu}$ nedenle portakal kabuğundan elde edilen esansiyel yağ ve hidrosollerin bu özelliklerinden gida endüstrisinde pek çok alanda yararlanılabilir.

\section{KAYNAKLAR}

[1] Z. Król, K. Marycz, D. Kulig, M. Maredziak and A. Jarmoluk, "Cytotoxicity, bactericidal, and antioxidant activity of sodium alginate hydrosols treated with direct electric current," International Journal of Molecular Sciences, vol. 18, no. 3, pp. 678-697, 2017.

[2] F. Törnük and E. Dertli, "Decontamination of Escherichia coli O157:H7 and Staphylococcus aureus from fresh-cut parsley with natural plant hydrosols," Journal of Food Processing and Preservation, vol. 39, no. 6, pp. 1587-1594, 2015.

[3] A. Acheampong, L. Borquaye, S. O. Acquaah, J. Osei-Owusu ve G. Tuani, "Antimicrobial activities of some leaves and fruit peels hydrosols," International Journal of Chemical and Biomolecular Science, vol. 1, no. 3, pp. 158-162, 2015.

[4] S. N. El, N. Karagözlü, S. Karakaya and S. Sahin, "Antioxidant and antimicrobial activities of essential oils extracted from Laurus Nobilis L. leaves by using solvent-free microwave and hydrodistillation," Food and Nutrition Sciences, vol. 5, pp. 97-106, 2014.

[5] L. Tabti, M. A. Dib, N. Djabou, N. G. Benyelles, J. Paolini, J. Costa, and A. Muselli, "Control of fungal pathogens of Citrus sinensis L. by essential oil and hydrosol of Thymus capitatus L." Journal of Applied Botany and Food Quality, vol. 87, pp. 279-285, 2014.

[6] A. Özkan and A. Erdoğan, "A comparative evaluation of antioxidant and anticancer activity of essential oil from Origanum onites (Lamiaceae) and its two major phenolic components," Turkish Journal of Biology, vol. 35, no.6, pp. 735-742, 2011.

[7] S. D'Amato, A. Serio, C. C. Lopez and A. Paparella, "Hydrosols: Biological activity and potential as antimicrobials for food applications," Food Control, vol. 86, pp. 126-137, 2018.

[8] C. Labadie, C. Ginies, M. H. Guinebretiere, C. Renard, C. Cerutti and F. Carlin, "Hydrosols of orange blossom (Citrus aurantium), and rose flower (Rosa damascena and Rosa centifolia) support the growth of a heterogeneous spoilage microbiota," Food Research International, vol. 76, pp. 576-586, 2015. 
[9] F. Törnük, H. Cankurt, İ. Ozturk, O. Sağdıç, O. Bayram and H. Yetim, “ Efficacy of various plant hydrosols as natural food sanitizers in reducing Escherichia coli O157:H7 and Salmonella Typhimurium on fresh cut carrots and apples" International Journal of Food Microbiology, vol. 148, no. 1, pp. 30-35, 2011.

[10] T. Lante and F. Tinello, "Citrus hydrosols as useful by-products for tyrosinase inhibition," Innovative Food Science and Emerging Technologies, vol. 27, pp.154-159, 2015.

[11] M. Zuzarte, M. J. Gonçalves, C. Cavaleiroa, M. T. Cruz, A. Benzarti B. Marongiud, A. Maxia, A. Piras and L. Salgueiroa, "Antifungal and anti-inflammatory potential of Lavandula stoechas and Thymus herba-barona essential oils," Industrial Crops and Products, vol. 44, pp. 97-103, 2013.

[12] E. Ndiaye, M. Gueye, I. Ndiaye, S. Diop, M. Diop, A. Thiam, M. Fauconnier ve G. Lognay, "Chemical composition of distilled essential oils and hydrosols of four senegalese citrus and enantiomeric characterization of chiral compounds" Journal of Essential Oil Bearing Plants, vol. 20, no. 3, pp. 820- 824, 2017.

[13] A. Ammar, A. Lebrihi, F. Mathieu, M. Romdhane and F. Zagrouba, "Chemical composition and in vitro antimicrobial and antioxidant activities of Citrus aurentium L. flowers essential oil (Neroli oil)," Pakistan Journal of Biological Sciences, vol. 15, no. 21, pp. 1034-1040, 2012.

[14] S. G. Deans and G. Ritchie, "Antibacterial properties of plant essential oils," International Journal of Food Microbiology, vol. 5, no. 2, pp. 165-180, 1987.

[15] R. Apak, K. Güçlü, M. Özyürek and S. E. Karademir, "Novel total antioxidant capacity index for dietary polyphenols and vitamins $\mathrm{C}$ and $\mathrm{E}$, using their cupric ion reducing capability in the presence of neocuproine: Cuprac method," Agricultural Food Chemistry, vol. 52, no. 26, pp. 7970-7981, 2004.

[16] O. Okan, H. Varlıbaş, M. Öz ve İ. Deniz, "Antioksidan analiz yöntemleri ve doğu karadeniz bölgesinde antioksidan kaynağı olarak kullanılabilecek odun dıșı bazı bitkisel ürünler," Kastamonu Üniversitesi Orman Fakültesi Dergisi, c.13, s. 1, ss. 48-59, 2013.

[17] R. Lemouchi, C. Selles, M. E. A. Dib, N. Benmansour, A. Allal, B. Tabti and K. Ouali, "Chemical Composition and Antioxidant Activity of Essential Oil and Hydrosol Extract Obtained by Hydrodistillation (HY) and Liquid-Liquid Extraction (LLE) of Psoralea bituminosa," Journal of Herbs, Spices \& Medicinal Plants, vol. 23, no. 4, pp. 299-307, 2017.

[18] L. Espina, M. Somolinos, S. Lorán, P. Conchello, D. García and R. Pagán, "Chemical composition of commercial citrus fruit essential oils and evaluation of their antimicrobial activity acting alone or in combined processes," Food Control, vol. 22, no. 6, pp. 896-902, 2011

[19] M. Swamy, M. S. Akhtar and U. A. Sinniah, " Antimicrobial properties of plant essential oils against human pathogens and their mode of action: An Updated Review," Evidence-Based Complementary and Alternative Medicine, 2016.

[20] B. Bozin, N. M. Dukic, N. Simin and G. Anaçkov, "Characterization of the volatile composition of essential oils of some Lamiaceae spices and the antimicrobial and antioxidant activities of the entire oils," Journal of Agricultural and Food Chemistry, vol. 54, no. 5, pp. 1822-1838, 2006. 
[21] H. Bendaha, B. Bouchal, I. E. Mounsi, A. Salhi, M. Berrabeh, M. E. Bellaoui and M. Mimouni, "Chemical composition, antioxidant, antibacterial and antifungal activities of peel essential oils of Citrus aurantium grown in Eastern Morocco," Der Pharmacia Lettre, vol. 8, no. 4, pp. 239-245, 2016.

[22] H-S. Choi, H. S. Song, H. Ukeda and M. Sawamura, "Radical-scavenging activities of Citrus essential oils and their components: detection using 1,1-diphenyl-2-picrylhydrazyl," Journal of Agricultural and Food Chemistry, vol. 48, no. 9, pp. 4156-4161, 2000.

[23] R. Belabbes, M. E. A Dib, N. Djabou, F. Ilias, B. Tabti, J. Costa and A. Muselli, "Chemical variability, antioxidant and antifungal activities of essential oils and hydrosol extract of Calendula arvensis L. from western Algeria," Chemistry \& biodiversity, vol. 14, no. 5, 2017. 